\title{
Complementary and alternative medicine (CAM) use in advanced cancer: a systematic review
}

\author{
Tracy L. Truant, RN, MSN, ${ }^{1}$ Antony J. Porcino, BSc, $\mathrm{PhD},{ }^{1}$ \\ Brenda C. Ross, RN, BSN, ${ }^{2}$ Margurite E. Wong, RN, MSN, ${ }^{2, *}$ and \\ Carla T. Hilario, RN, $\mathrm{MSN}^{1}$
}

Complementary Medicine Education and Outcomes (CAMEO) Research Program, ${ }^{1}$ University of British Columbia School of Nursing, Vancouver, British Columbia, Canada; ${ }^{2}$ British Columbia Cancer Agency, Vancouver, British Columbia, Canada

This systematic review synthesizes knowledge about the use of complementary and alternative medicine (CAM) among advanced cancer patients. EBSCO and Ovid databases were searched using core concepts, including advanced cancer, CAM, integrative medicine, and decision-making. Articles included in the final review were analyzed using narrative synthesis methods, including thematic analysis, concept mapping, and critical reflection on the synthesis process. Results demonstrate that advanced cancer patients who are younger, female, more educated, have longer duration of disease, and have previously used CAM are more likely to use CAM during this stage of illness. Key themes identified include patterns of and reasons for use; and barriers and facilitators to informed CAM decision-making. Knowledge regarding the use of CAM in advanced cancer remains in its nascent stages. Findings suggest a need for more research on understanding the dynamic process of CAM decision-making in the advanced cancer population from the patients' perspective.

$\mathrm{U}$ $\mathrm{p}$ to $93.1 \%$ of people report using some form of complementary and alternative medicine (CAM) during their cancer experience. ${ }^{1-33}$ Although the use of CAM in the general cancer population has been well documented over the past two decades, ${ }^{8,13,21,34-51}$ a comprehensive review regarding the use of CAM in the advanced cancer population has not been published. The diagnosis of advanced cancer represents a shift in the focus of treatment

Manuscript received October 23, 2012; accepted April 8, 2013 Correspondence Tracy L. Truant, RN, MSN, Doctoral Student, UBC School of Nursing and Co-Investigator, Complementary Medicine Education and Outcomes (CAMEO) Research Program, T201-2211 Wesbrook Mall, Vancouver, BC Canada V6T 2B5 (tracy.truant@nursing.ubc.ca).

Disclosures The authors have no conflicts to disclose. Funding for the CAMEO Research Program was received from the Lotte and John Hecht Memorial Foundation. Ms. Truant is a recipient of the Canadian Institute of Health Research (CIHR) Frederick Banting and Charles Best Canada Graduate Scholarships - Doctoral Award; Izaak Walton Killam Memorial Doctoral Fellowship; Canadian Institute of Health Research (CIHR) Psychosocial Oncology Research Training (PORT) Fellowship, the University of British Columbia FourYear Fellowship and the Canadian Nurses Foundation TD Meloche Monnex Scholarship.

*Ms Wong is now with the Vancouver Coastal Health Authority, Pacific Spirit Community Health Centre, Vancouver, British Columbia, Canada

J Support Oncol 2013;11:105-113 @ 2013 Frontline Medical Communications DOI: 10.12788/i.suponc.0011 and care from cure to palliation. ${ }^{52}$ Advancedcancer patients have reported increased levels of distress and symptom burden with poorer quality of life compared to those with curative or early stage disease. ${ }^{53,54} \mathrm{~A}$ growing body of research has identified increased prevalence of CAM use in the advanced-cancer population to address these issues and achieve other personal aims. ${ }^{11,12,15,18,21,23,24,27,28,32-34,45,46,55-58}$ Despite advanced stage disease being identified as one of the most common factors predicting CAM use, ${ }^{11,13,15,21,28,45,49,56-58}$ few studies have examined the unique needs and specific behaviors related to CAM use in this population. Given the complexity in caring for people with advanced cancer and a goal to provide evidence-informed CAM decision support, understanding the unique CAMrelated needs of this population will be valuable to oncology health care providers (HCPs). In this review, we seek to describe the factors, reasons, and decision-making process used by advanced-cancer patients to use CAM.

CAM is defined as a group of diverse medical and health care systems, practices, and products that are not presently considered part of conventional medicine. ${ }^{59} \mathrm{CAM}$ therapies are grouped into 5 categories: body based (eg, chiropractic, 
massage), mind-body based (eg, meditation, relaxation), energy based (eg, acupuncture, Reiki), biological products (eg, herbs; vitamins and minerals; natural health products), and whole systems (eg, naturopathy, traditional Chinese medicine)..$^{59}$

To capture the diversity of the methodologies and approaches used in current studies on CAM and advanced cancer, techniques drawn from systematic mixedstudies reviews are used in this paper. ${ }^{60}$ Drawing from qualitative, quantitative, and mixed-method studies in the literature, the review asks the broad research question, "What does the published evidence tell us about the use of CAM by advanced cancer patients?" The aim of this paper is to synthesize existing knowledge about CAM use by patients with advanced cancer to offer insight to further inform research and care.

\section{Methods}

The basic relevant definitions, search terms and strategy, the screening process including inclusion and exclusion criteria, and analysis approach were established a priori, based on the research question, and iteratively refined by consensus to address issues that arose as the articles were reviewed. $A d-$ vanced cancer was defined as beginning at the point in the cancer trajectory when treatment and care shifts from curative to palliative intent and extends for the remainder of one's life. ${ }^{52}$ CAM was defined as above. ${ }^{59}$

\section{Identification of relevant literature}

EBSCO and OVID databases (CINAHL, PsycInfo, MEDLINE, EBM Reviews, and Embase) were searched for relevant English language research articles with adult populations published from January 1990 to February 2013. Search terms were based on review of the Medical Subject Headings (MeSH). ${ }^{61}$ Two broad categories of search terms were selected and combined:

- advanced cancer: neoplasm, cancer, metastatic, incurable, palliative care, terminal care, advanced care, and advanced;

- CAM: complementary medicine, complementary therapy, alternative therapy, and integrative medicine.

Retrieved citations were tabulated in database files documenting the selection process, including the specific reasons for article exclusions.

\section{Selection of the literature}

Only original empirical and qualitative research studies, secondary analysis of empirical data, and systematic reviews of CAM use by advanced cancer patients were included. Studies examining outcomes of specific CAM treatments (eg, clinical trials, case studies, treatment center programs) were excluded. Grey literature also was excluded, as it has not been shown to yield significant literature for systematic reviews in the palliative population. ${ }^{62}$
Studies combining individuals with noncurative and $\mathrm{cu}^{-}$ rative disease as well as advanced or locally advanced cancers were excluded if the results did not distinguish between the 2 groups. Studies addressing locally advanced cancers were included if all of those study participants were identified as homogeneously noncurable. ${ }^{63}$ Studies conducted in countries where CAM is potentially an integral part of health care were excluded because making comparisons of CAM use across these and Western-medicine countries may be inequitable and difficult to interpret. Therefore, only articles from North America, Europe (including Turkey and Israel $)^{64}$ and Australia were included.

Two authors independently reviewed all abstracts for possible inclusion. Potentially relevant articles were retrieved and reviewed through full-text screening to determine relevance and concurrence with the inclusion criteria and definitions. Additional relevant articles were identified from the citations within the selected studies.

\section{Appraisal and data extraction}

Methodological quality appraisal of the included studies used the scoring system for mixed studies reviews developed by Pluye et al. ${ }^{60}$ For appraisal of systematic reviews, the PRISMA (Preferred Reporting Items for Systematic Reviews and Meta-Analyses) 2009 27-point checklist was used to assess review thoroughness. ${ }^{65}$ All authors appraised each article; all scores were then reviewed by one author and discussed with the group to achieve consensus. While no articles were excluded based on the quality score, the quality issues were considered when reviewing the results.

\section{Methods of synthesis}

The narrative synthesis described in this approach includes preliminary analysis; exploration of relationships; assessment of the robustness of the synthesis; and, where appropriate, theory development. ${ }^{66}$ Due to the exploratory nature of this analysis, theory development was not undertaken. Synthesis began with a review of the data in a table of descriptive characteristics and key findings available online (Table S1; http://tinyurl.com/monlanl). Two authors conducted the thematic analysis using general qualitative processes; the derived main themes were discussed and validated with the group.

\section{Results}

\section{Identification and selection of the literature}

The identification and selection process of the bibliographic search are summarized in the Figure, using a PRISMA flow diagram. ${ }^{65}$ Screening of the 393 unique identified articles left 47 articles included in this review. Extracted descriptive characteristics of those 47 studies (including the sample; methodology; method of data collection and analysis; and quality appraisal scores) and the key findings are available online (Table S1; http://tinyurl.com/monlanl). 


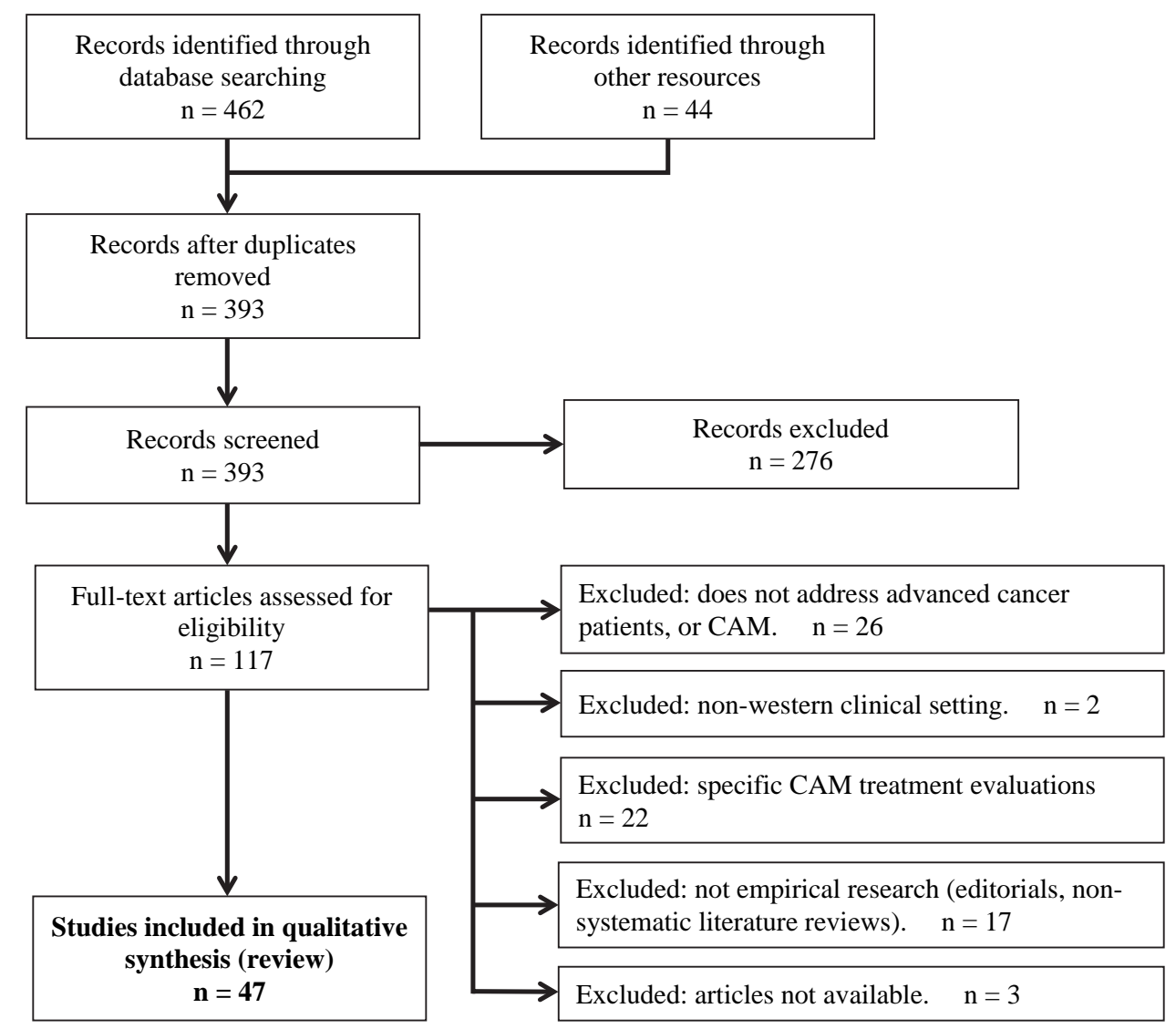

FIGURE PRISMA flowchart.

\section{Thematic analysis}

Three main themes were extracted from the selected literature, including patterns of CAM use; reasons for CAM use; and barriers and facilitators of informed CAM decision-making in the advanced cancer population (Table).

Patterns of CAM use. Within patterns of CAM use, 3 subthemes were extracted from the data: prevalence; sociodemographic and disease factors; and psychological factors.

Prevalence. Researchers documented a wide range of CAM use prevalence in the advanced cancer population, from $15 \%{ }^{17}$ to $100 \%{ }^{2}$ Use of biologic CAM therapies, particularly vitamins and herbal remedies, were the most frequently reported. ${ }^{4-6,9,10,14,18-20,27,28,30-32,45,46,67}$ Often nonbiologic therapies like spiritual practices, exercise, and diet changes were excluded from measures of CAM prevalence, making comparisons across studies difficult. Ingested biologic CAM therapies were frequently used concurrently with conventional cancer treatment, even during phase I clinical trails. This raised concerns about potential interactions and the impact on clinical trial research outcomes. ${ }^{6,10,18,32}$ The use of multiple concurrent CAM therapies was common. $3,4,9,14,18,26,27,32$

Socio-demographic and disease factors. Advanced stage and longer duration of disease, $3,15,27,28,32,45,68$ female gender, ${ }^{3,16,18,43}$ younger age, ${ }^{3,9,10,19,27,45,56,68}$ higher education, ${ }^{3,9,26,45,56,68}$ and previous CAM use $23,29,45$ showed positive associations with current CAM use in many studies, although these findings were inconsistent. For example, 2 studies reported that participants with early stage cancer compared to advanced stage were equally ${ }^{69}$ or more ${ }^{43}$ inclined to use CAM.

No significant association between types of CAM use and gender was identified. ${ }^{6,19}$ As disease progressed, CAM users with higher education chose more biologic and "radical CAM therapies" (eg, coffee enemas, magnet therapy, high dose vitamin C). ${ }^{11,45}$ Some geographical trends in CAM use were noted, related to accessibility (eg, high use of naturopathy by people living near a naturopathic college ${ }^{15,16}$ ) and possible cultural traditions (eg, high use of stinging nettle across Turkey ${ }^{2,12,28,56,70}$ ). 
TABLE Main themes of CAM use in advanced cancer

Themes of CAM Use
Patterns of CAM use

a. Prevalence: CAM use and numbers of CAM therapies used, particularly biological products (eg, natural health products, herbs), increases in the advanced cancer population.

\section{b. Sociodemographic and disease factors}

i. Previous CAM use, longer duration of disease, younger age, female gender, and higher education are positively associated with CAM use.

ii. As disease progresses, non-evidence based CAM use increases.

iii. Accessibility (insured services; available locally; ease of use) influences CAM use.

\section{c. Psychological factors}

i. Symptom distress, anxiety and depression, decreased emotional or social well being, decreased quality of life, desire for control and better awareness of prognosis are positively associated with CAM use.

\section{Reasons for CAM use}

a. Cure (ie, fight disease/shrink tumor, enhance immune response, synergize conventional treatment, or detoxify body)

b. Non-curative benefits (ie, improve well-being and quality of life; increase control; reduce stress; boost energy; address unmet emotional, psychological or spiritual needs)

c. Beliefs about causes of cancer, curability of cancer, and spiritual faith are related to advanced cancer patient's reasons for CAM use.

i. Those holding positive illusory beliefs about the curability of their cancer may use CAM as a positive coping mechanism for life-limiting illness

ii. Those who believe their cancer is incurable may use CAM as a pragmatic problem-solving approach.

iii. Spiritual faith may be associated with either a positive coping style, or an indicator of distress.

d. Satisfaction with conventional treatment, care, or relationship with health care providers may be inversely associated with CAM use.

Barriers and facilitators to informed CAM decision-making

a. Sources of CAM information include family and friends, social networks, media (including internet), health food store staff and CAM practitioners.

b. Conventional health care providers were consulted infrequently for information and decision support; ingested CAM therapies most commonly discussed.

c. Non-disclosure of CAM by patients to health care providers is common, including patients on Phase I clinical trials

Abbreviation: CAM, complementary and alternative medicine.

Cost and ease of use were identified as important factors associated with CAM use. Two studies indicated that cost was an important factor in the decision to use a particular CAM therapy. ${ }^{7,19}$ The cost of CAM was judged relative to the outcomes achieved. ${ }^{7}$ However, when CAM costs were high, people used CAM less frequently. ${ }^{7,19}$

Therapies that required little effort, with minimal side effects, available locally and covered by health insurance, (eg, in Washington state: chiropractic, naturopathy, massage therapy, and acupuncture) were used frequently. ${ }^{15,16,18,45}$ Two studies showed that as disease progressed and physical function declined, decreased use of CAM was reported, possibly due to the required effort necessary to use or access the CAM. ${ }^{16,23}$

Psychological factors. Psychological factors associated with CAM use in the advanced cancer population included higher anxiety and depression, ${ }^{1,4,10,26}$ decreased subjective well-being, ${ }^{4}$ decreased emotional and social well-being and quality of life, ${ }^{10,11}$ and being more aware of their prognosis or impending death. ${ }^{10}$

Reasons for CAM use. The reasons for using CAM identified by patients with advanced cancer were not consistently reported or explored. . $13,21,22,28,34,56$ When reported, reasons varied, having been influenced by beliefs about the causes of and/or curability of one's cancer, ${ }^{20,30,38,67,71}$ perceived effectiveness of and satisfaction with conventional cancer treatment, ${ }^{4,27,38}$ perceived value and goals for CAM use, $4,5,30$ and unmet physical and/or psychological needs. ${ }^{4,5,7,20,26,32,33,69}$

Improving chances for a cure. Numerous studies identified improving chance for a cure, either directly or indirectly, as a reason for using CAM. In 9 studies, patients believed that CAM use might increase chance of survival by directly fighting the disease or shrinking the tumor. . $^{, 7,18,19,26,29,31,45,69}$ Indirect means included facilitating/synergizing conventional treatment outcomes, ${ }^{45}$ and boosting immunity and/or detoxifying one's body that has been depleted from the cancer and/or conventional treatments. ${ }^{5,18,31-33}$ Two studies offered insight into how CAM use for the purpose of cure shifted across the cancer trajectory from early to advanced stages. ${ }^{14,45}$ However, they did not explore the underlying beliefs or other factors underpinning these dynamic decisions to use CAM specifically for a cure.

Benefits other than cure. A wide range of noncurative benefits were identified specific to advanced cancer patients, including to improve well-being and feel healthier, ${ }^{7,33,45,72}$ promote relaxation and reduce stress, ${ }^{18,26,29,33}$ boost energy and improve quality of life, $, 4,5,7,18,19,26,33,69$ and symptom and treatment side-effect management. ${ }^{4,5,7,18,19,26,29,31,33,69}$ Some patients reported using CAM to address unmet emotional, psychological and spiritual needs; $;^{1,4,5,7,21,29,30,33,45,73}$ to believe they had done everything possible to fight their cancer, ${ }^{5,18,46}$ and to improve a sense of control over their illness. ${ }^{32,67,71}$ 
Beliefs about the curability of cancer. A number of studies explored how beliefs about the causes of and/or curability of cancer influenced decisions to use CAM. Yates et $\mathrm{al}^{30}$ found that beliefs about alternative causes of cancer were positively correlated with CAM use and were at variance from those held by conventional practitioners. Four studies ${ }^{4,27,67,71}$ investigated the relationship between belief in the curability of one's disease to CAM use, providing insight into 2 different groups of CAM users. The first group held beliefs that their cancer was curable (despite conventional medical opinion to the contrary) and continued to be committed users of CAM to cope with life-limiting illness. ${ }^{67,71}$ The second group of $\mathrm{pa}^{-}$ tients believed their cancer was incurable (congruent with conventional medical opinion) yet continued to use CAM for the purpose of cure. ${ }^{4}$ For these patients, using CAM was more about a pragmatic approach to active problem solving, coping, and "trying something else" in the face of adversity. ${ }^{46,74}$

Role of spirituality. Spiritual well-being (existential well-being and faith) was identified in one study as significantly associated with CAM use for the purpose of cure. ${ }^{29}$ In this study, the majority of CAM users sought a cure from their CAM use; reported increased spiritual faith; decreased existential well-being; ${ }^{29}$ and may have had higher unmet spiritual needs. For this reason, CAM use was a potential marker for increased distress. ${ }^{29} \mathrm{Con}-$ versely, another study ${ }^{27}$ found that CAM users showed a more active coping style through religion and seeking personal meaning in the illness; in addition, the users were not more distressed than those uninterested in CAM. It is unclear, however, whether or not the CAM users were seeking a cure or to address noncurative aims.

Satisfaction with conventional medicine. People who reported lower levels of satisfaction with conventional medicine were more likely to use $\mathrm{CAM}^{5,19,27,75}$ or to decline conventional treatment. ${ }^{4}$ Without adequate support or advice from $\mathrm{HCPs}_{-}$or effective conventional treatment - advanced cancer patients may use CAM in response to the inability of conventional medicine to treat the disease and/or offer satisfactory supportive care., ${ }^{5,27}$

Barriers and facilitators to informed CAM decision-making. Although well described in studies with early stage and mixed (early/advanced) cancer populations, ${ }^{35,55,76-78}$ none of the studies in this review explored or described the dynamic CAM decision-making process of advanced cancer patients. However, 2 key subthemes related to CAM decision-making in the advanced cancer population were identified, including sources of CAM information and communicating with conventional HCPs.
Source of CAM information. Across studies, patients reported using multiple sources of information to learn about CAM. Friends and family, particularly those with cancer experience, were the most frequent source cited. $7,18,21,26,28,31-33,56$ In order of decreasing frequency, other sources of CAM information included social groups (eg, church, support groups), ${ }^{18}$ media (eg, internet, television, and self-help literature), ${ }^{18,19,26,28,56}$ health food store staff, and CAM practitioners. ${ }^{18,19}$ Conventional HCPs were consulted infrequently ( $0-16 \%$ across studies) for CAM information. ${ }^{10,18,19,26,31}$ The reasons why advanced cancer patients used their social and lay networks more frequently than HCPs as sources of CAM information were not explored in these studies.

Communication with conventional health care providers. Previous research with early stage and mixed (early/advanced) cancer populations has shown that informed CAM decision-making requires open and respectful communication; and shared decision-making between $\mathrm{pa}^{-}$ tients and HCPs. ${ }^{77,79-87}$ In this review, while some HCPs did communicate with patients about CAM, most studies reported communication gaps. Patients using ingested therapies and patients with prostate cancer discussed their CAM use with physicians; however, noningested therapies were not discussed. ${ }^{18,26,45,56}$ Many studies reported that the HCPs never asked about the use of CAM. When discussion did take place, it is unclear as to whether the patient or $\mathrm{HCP}$ opened the dialogue or whether a shared decision-making process was used that was inclusive of patients' beliefs, values, and goals for CAM use. ${ }^{18,26,32,33,45,56,88}$ Poor communication encounters with $\mathrm{HCPs}$ in one study influenced advanced cancer patients' decisions to use CAM. ${ }^{20}$ Only 2 studies reported conventional HCPs making recommendations to advanced cancer patients about the use of CAM. ${ }^{32,45}$

Patients in phase I clinical trials represented a unique subgroup within this review. ${ }^{6,10,18} \mathrm{Up}$ to $23 \%$ of these patients did not fully disclose their CAM use to physicians, ${ }^{18}$ commonly reporting that the topic of CAM was never introduced despite a preference for shared decisionmaking about CAM. ${ }^{10,18}$ No additional studies could be located that specifically explored advanced cancer patients' unmet needs or perspectives on CAM decision-making.

\section{Limitations}

The comparability of study results within this review is limited by the varying definitions of CAM and differences across health care systems (eg, socialized vs private medicine) where studies were conducted. Study samples were heavily weighted with women with breast cancer since they are among the highest users of CAM. . $^{8,41,48}$ 
Recruitment across studies was largely from conventional care settings, potentially biasing the sample to under report CAM use and by not including perspectives of those not actively participating in conventional care. Comparisons across and between countries or health care systems also was not possible due to the limited number and heterogeneity of studies specifically focusing on advanced cancer and CAM.

Many excellent studies were excluded from this review because of the inability to clearly differentiate findings specifically about advanced cancer. Further, few qualitative studies met the inclusion criteria for this review, such as those highlighting the patients' perspectives, limiting understanding of the CAM decision-making process of advanced cancer patients. Finally, although the challenges in conducting a narrative synthesis integrating qualitative and quantitative data necessarily limits the depth of results presented, it does offer opportunities to suggest clinical implications and new paths for research.

\section{Discussion}

This review supports evidence of increased CAM use in the advanced stages of cancer; ${ }^{11,12,15,18,21,23,24,27,28,32-34,38,45,46,56-58}$ providing insight into the associated socio-demographic, physical, and psychosocial factors; reasons for use; and personal beliefs that may affect CAM decision-making. However, literature identifying CAM decision-support needs and the dynamic process of CAM decision-making from the perspective of people living with advanced cancer is in its nascent stages. Previous research with early stage and/or mixed (early/advanced) cancer populations ${ }^{35,38,76-78}$ suggest that CAM decision-making can be an anxiety-laden experience for patients that shifts as the individual and social context changes. ${ }^{77}$ In the advanced cancer populationwhere anxiety and distress may be high, physical decline prominent, and one's social network potentially shifting ${ }^{53,54}$ it can be postulated that the process of CAM decisionmaking by advanced cancer patients may have unique aspects to be considered when designing CAM decisionsupport interventions.

The differing perspectives between HCPs and some advanced cancer patients regarding the curability of cancer within this review highlighted the phenomenon of maintaining uncertainty and promoting hope in the face of life-limiting illness. Beadle et al's $(2004)^{71}$ concept of illusions in advanced cancer, where patients facing lifelimiting illness positively appraised their situation despite biomedical opinion to the contrary, can be considered an adaptive process and a feature of normal psychological behavior. $^{89}$

For many advanced cancer patients, being realistic while maintaining hope in the face of life-limiting illness can be irreconcilable if they cannot maintain some ambiguity about the future. ${ }^{54,90} \mathrm{CAM}$ use can provide ambiguity, hope, psycho-spiritual well-being, and quality of life. ${ }^{54,91}$ It can be viewed as a positive coping strategy in the advanced cancer population, a finding also validated in other disease stages. ${ }^{27,42,74,92}$

Advanced cancer is frequently accompanied by distress and unmet physical, psychological, social, spiritual, and communication needs that often cannot be adequately addressed within the conventional health care system. ${ }^{53}$ CAM use for symptom management or to improve physical and/or spiritual well-being and quality of life may reflect a pragmatic approach to managing distress or unmet needs. Whether CAM use signals distress, empowerment, or a strategy to maintain hope merits further investigation in the advanced cancer population to ensure the phenomenon is understood and appropriately supported by HCPs. ${ }^{93}$

Preferences for lay information sources to inform CAM decisions may be another strategy to manage the tension between the reality of one's situation and maintaining hope. Information from conventional HCPs that does not balance available evidence with patients' beliefs, goals, and preferences for CAM use may dash hope and be counterproductive to making evidence-informed decisions. ${ }^{82}$ Future exploration of preferences for lay information sources - and its relationship to helpful and unhelpful communication by HCPs about CAM - may offer an alternative perspective to inform how best to support CAM decision-making in advanced cancer patients. ${ }^{79-87}$

The nondisclosure of CAM use by patients in phase I trials encapsulates many of these issues, signaling possible lack of trust in their HCP, a strategy to maintain hope in the face of adversity, potential distress, fear of abandonment by their HCP, or other unknown reasons. Nondisclosure must be explored further from the patient's perspective to understand the support needed to address the individual's unique CAM information and decision-support needs and goals while maintaining the integrity of the trials results.

\section{Directions for future research}

Several gaps exist in the content and methodology associated with current knowledge about CAM use in the advanced cancer population. A common definition of CAM must be agreed upon and used consistently across studies for comparisons to be made. Studies that specifically target the advanced cancer population, including qualitative methodologies that are inclusive of the patient and family perspectives, will add depth and richness to the current knowledge. Mixed-methods studies will be important to conduct in order to examine the relationship and directionality of concepts related to 
advanced cancer and CAM, such as quality of life, control, knowledge of poor prognosis, spiritual faith, distress, empowerment, and coping. Finally, longitudinal studies that capture the dynamic nature of CAM decisionmaking and the interplay of factors (eg, beliefs, unmet needs, communication style and preferences, role of $\mathrm{HCPs}$ ) that influence CAM use across the trajectory between curative and noncurative disease will add significant understanding to this area.

\section{Clinical implications}

Advanced cancer patients commonly use CAM. Yet most do not discuss their CAM use with their conventional $\mathrm{HCPs}$, raising concerns about safety and potential missed benefits of evidence-based CAM. It is essential for HCPs to discuss CAM use with all patients, assessing individuals' beliefs and values and goals for CAM use, including conventional treatment and care. ${ }^{77,79-87,94}$ Understanding patterns of CAM use in the advanced cancer population and specifically identifying those who are more likely to use CAM (ie, female, younger age, with higher education, psychological or physical symptoms, dissatisfaction with conventional care, longer disease duration, and previous CAM use) is important to understand and assess. Phase I clinical trials patients merit special consideration and support to discuss their CAM use and to consider using nonbiological CAM therapies that will achieve their CAM-related goals. Assessments should also include psychosocial factors that may coincide with CAM use (eg, distress, need for control, spirituality) as well as CAM use as a positive coping strategy to manage the tension between a realistic appraisal of one's situation and the preservation of hope.

The popularity of herbal/biological-therapy use by the advanced cancer population identified in this review reinforces the need for HCPs to initiate open and unbiased communication specifically about these ingested products. Although new evidence emerges daily, safety and efficacy data on many herbal/biological products remains limited and manufacturing processes in many countries are variably regulated. ${ }^{95,96} \mathrm{HCPs}$ must actively communicate with patients about the use of herbal/biological products and other CAM therapies in a way that promotes safety while continuing to preserve hope and acknowledging the patients' beliefs, values, and goals. ${ }^{82,85,86}$

\section{Conclusion}

Patients living with advanced cancer in Western countries frequently use CAM, particularly biologic therapies, after learning about accessible CAM therapies through their support networks and media. Greater CAM use is associated with longer duration of disease, female gender, higher education, spiritual belief, younger age, psychosocial or physical symptoms, and dissatisfaction with conventional cancer care. Patients frequently do not disclose their CAM use to HCPs even in the context of phase I clinical trials, raising concerns about patient safety and clinical trial outcomes. HCPs have an opportunity to explore with patients whether use of CAM signals distress or a sign of hope and empowerment. HCPs may also facilitate shared decision-making that is compatible with the patient's values and goals regardless of stage of illness.

Supplemental material: Table S1, Descriptive characteristics, is available online at http://tinyurl.com/ monlanl.

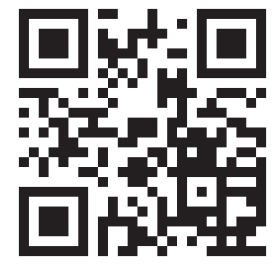

\section{References}

1. Balboni TA, Vanderwerker LC, Block SD, et al. Religiousness and spiritual support among advanced cancer patients and associations with end-of-life treatment preferences and quality of life. J Clin Oncol. 2007;25(5):555-560.

2. Can G, Erol O, Aydiner A, Topuz E. Quality of life and complementary and alternative medicine use among cancer patients in Turkey. Eur J Oncol Nurs. 2009;13(4):287-294.

3. Corbin LW, Mellis BK, Beaty BL, Kutner JS. The use of complementary and alternative medicine therapies by patients with advanced cancer and pain in a hospice setting: a multicentered, descriptive study. J Palliat Med. 2009;12(1):7-8.

4. Correa-Velez I, Clavarino A, Barnett AG, Eastwood H. Use of complementary and alternative medicine and quality of life: changes at the end of life. Palliat Med. 2003;17(8):695-703.

5. Correa-Velez I, Clavarino A, Eastwood H. Surviving, relieving, repairing, and boosting up: reasons for using complementary/alternative medicine among patients with advanced cancer: a thematic analysis. J Palliat Med. 2005;8(5):953-961.

6. Dy GK, Bekele L, Hanson LJ, et al. Complementary and alternative medicine use by patients enrolled onto phase I clinical trials[published correction appears in J Clin Oncol. 2005;23(1):248]. J Clin Oncol. 2004;22(23):4810-4815.

7. Eliott JA, Kealey CP, Olver IN. (Using) complementary and alternative medicine: the perceptions of palliative patients with cancer. $J$ Palliat Med. 2008;11(1):58-67.

8. Ernst E, Cassileth BR. The prevalence of complementary/alternative medicine in cancer: a systematic review. Cancer. 1998;83(4): 777-782.

9. Gross AM, Liu Q, Bauer-Wu S. Prevalence and predictors of complementary therapy use in advanced stage breast cancer patients. J Onc Practice. 2007;3(6):292-295.

10. Hlubocky FJ, Ratain MJ, Wen M, Daugherty CK. Complementary and alternative medicine among advanced cancer patients enrolled on phase I trials: A study of prognosis, quality of life, and preferences for decision making. J Clin Oncol. 2007;25(5):548-554.

11. Jordan ML, Delunas LR. Quality of life and patterns of nontraditional therapy use by patients with cancer. Oncol Nurs Forum. 2001;28(7):1107-1113.

12. Kav S, Pinar G, Gullu F, et al. Use of complementary and alternative medicine in patients with gynecologic cancer: is this usage more prevalent? I Altern Complement Med. 2008;14(4):347-349.

13. Klafke N, Eliott JA, Wittert GA, Olver IN. Prevalence and predictors of complementary and alternative medicine (CAM) use by men in Australian cancer outpatient services. Ann Onc. 2012;23(6): 1571-1578. 
14. Kremser T, Evans A, Moore A, et al. Use of complementary therapies by Australian women with breast cancer. Breast. 2008; 17(4):387-394.

15. Lafferty WE, Bellas A, Baden AC, Tyree PT, Standish LJ, Patterson R. The use of complementary and alternative medical providers by insured cancer patients in Washington State. Cancer. 2004;100(7):1522-1530.

16. Lafferty WE, Tyree PT, Devlin SM, Andersen MR, Diehr PK. Complementary and alternative medicine provider use and expenditures by cancer treatment phase. Am J Manag Care. 2008;14(5): 326-334.

17. Maggiore RJ, Gross CP, Togawa K, et al. Use of complementary medications among older adults with cancer. Cancer. 2012;118(19): 4815-4823.

18. Naing A, Stephen SK, Frenkel M, et al. Prevalence of complementary medicine use in a phase 1 clinical trials program: the MD Anderson Cancer Center Experience. Cancer. 2011;117(22):51425150.

19. Oneschuk D, Fennell L, Hanson J, Bruera E. The use of complementary medications by cancer patients attending an outpatient pain and symptom clinic. J Palliat Care. 1998;14(4):21-26.

20. Oneschuk D, Hanson J, Bruera E. Complementary therapy use: a survey of community- and hospital-based patients with advanced cancer. Palliat Med. 2000;14(5):432-434.

21. Paltiel O, Avitzour M, Peretz T, et al. Determinants of the use of complementary therapies by patients with cancer. J Clin Oncol. 2001;19(9):2439-2448.

22. Ponholzer A, Struhal G, Madersbacher S. Frequent use of complementary medicine by prostate cancer patients. Eur Urol. 2003;43(6): 604-608.

23. Risberg T, Lund E, Wist E, et al. The use of non-proven therapy among patients treated in Norwegian oncological departments. A cross-sectional national multicentre study. Eur J Cancer. 1995; 31(11):1785-1789.

24. Risberg T, Lund E, Wist E. Use of non-proven therapies. Differences in attitudes between Norwegian patients with non-malignant disease and patients suffering from cancer. Acta Oncol. 1995;34(7): 893-898.

25. Risberg T, Vickers A, Bremnes RM, Wist EA, Kaasa S, Cassileth BR. Does the use of alternative medicine predict survival from cancer? Eur J Cancer. 2003;39(3):372-377.

26. Shen J, Andersen R, Albert PS, et al. Use of complementary/ alternative therapies by women with advanced-stage breast cancer. BMC Complement Altern Med. 2002;13;2:8.

27. Söllner W, Zingg-Schir M, Rumpold G, Fritsh P. Attitude toward alternative therapy, compliance with standard treatment, and need for emotional support in patients with melanoma. Arch Dermatol. 1997;133(3):316-321.

28. Tarhan O, Alacacioglu A, Somali I, et al. Complementaryalternative medicine among cancer patients in the western region of Turkey. J BUON. 2009;14(2):265-269.

29. Trinkaus M, Burman D, Barmala N, et al. Spirituality and use of complementary therapies for cure in advanced cancer. Psychooncology. 2011;20(7):746-754.

30. Yates PM, Beadle G, Clavarino A, et al. Patients with terminal cancer who use alternative therapies: their beliefs and practices. Sociol Health Ill. 1993;15(2):199-216.

31. Yildirim Y. Patterns of the use of complementary and alternative medicine in women with metastatic cancer. Cancer Nurs. 2010; 33(3):194-200.

32. Engdal SS, Steinsbekk AA, Klepp OO, Nilsen OG. Herbal use among cancer patients during palliative or curative chemotherapy treatment in Norway. Support Care Cancer. 2008;16(7):763-769.

33. Verhoef M. Complementary and alternative approaches in palliative care: why are advanced cancer patients using them? Prog Palliat Care. 2012;20(5):264-271.

34. Bishop FL, Rea A, Lewith H, et al. Complementary medicine use by men with prostate cancer: a systematic review of prevalence studies. Prostate Cancer Prostatic Dis. 2011;14(1):1-13.
35. Boon H, Brown JB, Gavin A, Kennard MA, Stewart M. Breast cancer survivors' perceptions of complementary/alternative medicine (CAM): making the decision to use or not to use. Qual Health Res. 1999;9(5):639-653.

36. Boon H, Stewart M, Kennard MA, et al. Use of complementary/ alternative medicine by breast cancer survivors in Ontario: prevalence and perceptions. J Clin Oncol. 2000;18(13):2515-2521.

37. Boon H, Brown JB, Gavin A. What are the experiences of women with breast cancer as they decide whether to use complementary/ alternative medicine. West J Med. 2000;173(1):39.

38. Boon H, Brown JB, Gavin A, Westlake K. Men with prostate cancer: making decisions about complementary/alternative medicine. Med Decis Making. 2003;23(6):471-479.

39. Boon H, Westlake K, Deber R, Moineddin R. Problem-solving and decision-making preferences: No difference between complementary and alternative medicine users and non-users. Complement Ther Med. 2005;13(3):213-216.

40. Boon HS, Olatunde F, Zick SM. Trends in complementary/alternative medicine use by breast cancer survivors: comparing survey data from 1998 and 2005. BMC Womens Health. 2007;7:4.

41. DiGianni LM, Garber JE, Winer EP. Complementary and alternative medicine use among women with breast cancer. J Clin Oncol. 2002;20(18 Suppl.):34S-38S.

42. Ernst E, Hung SK. Great expectations: what do patients using complementary and alternative medicine hope for? Patient. 2011; 4(2):89-101.

43. Fouladbakhsh JM, Stommel M, Given BA, Given CW. Predictors of use of complementary and alternative therapies among patients with cancer. Oncol Nurs Forum. 2005;32(6):1115-1122. doi: 10.1188/05.ONF.1115-1122.

44. Greenlee H, Kwan ML, Egras IJ, et al. Complementary and alternative therapy use before and after breast cancer diagnosis: the Pathways Study. Breast Cancer Res Treat. 2009;117(3):653-655.

45. Miller M, Boyer MJ, Butow PN, Gattellari M, Dunn SM, Childs A. The use of unproven methods of treatment by cancer patients: Frequency, expectations and cost Support Care Cancer. 1998;6(4): 337-347.

46. Salmenpera L. The use of complementary therapies among breast and prostate cancer patients in Finland. Eur J Cancer Care. 2002; 11(1):44-50.

47. Sewitch MJ, Rajput Y. A literature review of complementary and alternative medicine use by colorectal cancer patients. Complement Ther Clin Pract. 2010;16(1):52-56.

48. Sparber A, Wootton JC. Surveys of complementary and alternative medicine: Part II. Use of alternative and complementary cancer therapies. I Altern Complement Med. 2001;7(3):281-287.

49. Verhoef MJ, Balneaves LG, Boon HS, Vroegindewey A. Reasons for and characteristics associated with complementary and alternative medicine use among adult cancer patients: a systematic review. Integr Cancer Ther. 2005;4(4):274-286.

50. Wanchai A, Armer JM, Stewart BR. Complementary and alternative medicine use among women with breast cancer: A systematic review. Clin J Oncol Nurs. 2010;14(4):E45-E55.

51. Yates JS, Mustian KM, Morrow GR, et al. Prevalence of complementary and alternative medicine use in cancer patients during treatment. Support Care Cancer. 2005;13(10):806-811.

52. World Health Organization. Definition of palliative care. Geneva, Switzerland: World Health Organization; 2012

53. Higginson IJ, Costanini M. Dying with cancer, living well with advanced cancer. Eur I Cancer. 2008;44(10):1414-1424.

54. McClement SE, Chochinov HM. Hope in advanced cancer patients. Eur J Cancer. 2008;44(8):1169-1174.

55. Boon H, Westlake K, Stewart M, et al. Use of complementary/ alternative medicine by men diagnosed with prostate cancer: prevalence and characteristics. Urology. 2003;62(5):849-853.

56. Er O, Mistik S, Ozkan M, Ozturk A, Altinbas M. Factors related to complementary/alternative medicine use among cancer patients in central Anatolia. Tumori. 2008;94(6):833-837. 
57. Lee MM, Lin SS, Wrensch MR, Adler SR, Eisenberg D. Alternative therapies used by women with breast cancer in four ethnic populations. J Natl Cancer Inst. 2000;92(1):42-47.

58. Nagel G, Hoyer H, Katenkamp D. Use of complementary and alternative medicine by patients with breast cancer: observations from a health-care survey. Support Care Cancer. 2004;12(11):789796.

59. National Center for Complementary and Alternative Medicine. What is CAM? nccam.nih.gov. 2007. Available at: http://nccam. nih.gov/health/whatiscam/. Accessed March 1, 2008.

60. Pluye P, Gagnon MP, Griffiths F, Johnson-Lafleur J. A scoring system for appraising mixed methods research, and concomitantly appraising qualitative, quantitative, and mixed methods primary studies in Mixed Studies Review. Int J Nurs Stud. 2009;46(4):529546.

61. National Institutes of Health. Medical subject headings. 2013. Available at: www.nlm.nih.gov/mesh. Accessed February 142012.

62. Cook AM, Finlay AG, Edwards AG, et al. Efficiency of searching the grey literature in palliative care. J Pain Symptom Manage. 2001; 22(3):797-801.

63. MacDonald SM, Harris EE, Arthur DW, et al. ACR Appropriateness criteria locally advanced breast cancer. Breast J. 2011;17(6): 579-585.

64. WHO Regional Office for Europe. European observatory on health systems and policies. euro.who.int. 2013. Available at: http:// www.euro.who.int/en/who-we-are/partners/observatory/healthsystems-in-transition-hit-series. Accessed September 152012.

65. Moher D, Liberati A, Tetzlaff J, Altman DG; Prisma Group. Preferred reporting items for systematic reviews and meta-analyses: the PRISMA statement. Int J Surg. 2010;8(5):336-341.

66. Popay J, Roberts H, Sowden A, et al. Guidance on the conduct of narrative synthesis in systematic reviews. Results of an ESRC funded research project. Lancaster, UK: Institute for Health Research, Lancaster University; 2006:92.

67. Beadle GF, Yates PM, Najman JM, et al. Beliefs and practices of patients with advanced cancer: implications for communication. Br J Cancer. 2004;91(2):254-257.

68. Bishop FL, Yardley L. Constructing agency in treatment decisions: negotiating responsibility in cancer. Health. 2004;84(4):465-482.

69. Mirabeau-Beale KL, Kornblith AB, Penson RT, et al. Comparison of the quality of life of early and advanced stage ovarian cancer survivors. Gynecol Oncol. 2009;114(2):353-359.

70. Gözüm S, Tezel A, Koc M. Complementary alternative treatments used by patients with cancer in eastern Turkey. Cancer Nurs. 2003; 26(3):230-236.

71. Beadle GF, Yates PM, Najman JM, et al. Illusions in advanced cancer: the effect of belief systems and attitudes on quality of life. Psychooncology. 2004;13(1):26-36.

72. Smithson J, Britten N, Paterson C, Lewith G, Evans M. The experience of using complementary therapies after a diagnosis of cancer: A qualitative synthesis. Health (London). 2010;16(1):19-39.

73. Mao JJ, Cronholm PF, Stein E, Straton JB, Palmer SC, Barg FK. Positive changes, increased spiritual importance, and complementary and alternative medicine (CAM) use among cancer survivors. Integr Cancer Ther. 2010;9(4):339-347.

74. Söllner W, Maislinger S, DeVries A, Steixner E, Rumpold G, Lukas P. Use of complementary and alternative medicine by cancer patients is not associated with perceived distress or poor compliance with standard treatment but with active coping behavior: a survey. Cancer. 2000;89(4):873-880.

75. Dunwoody L, Smyth A, Davidson R. Cancer patients' experiences and evaluations of aromatherapy massage in palliative care. Int $J$ Palliat Nurs. 2002;8(10):497-504.

76. Balneaves LG, Truant TL, Kelly M, Verhoef MJ, Davison BJ. Bridging the gap: decision-making processes of women with breast cancer using complementary and alternative medicine (CAM). Support Care Cancer. 2007;15(8):973-983.
77. Balneaves LG, Weeks L, Seely D. Patient decision-making about complementary and alternative medicine in cancer management: context and process. Curr Oncology. 2008;15(Suppl 2):s24-s100.

78. Truant TL, Bottorff JL. Decision making related to complementary therapies: a process of regaining control. Patient Educ Couns. 1999; 38(2):131-142.

79. Ben-Ayre B, Visser A. The role of health care communication in the development of complementary and integrative medicine. $\mathrm{Pa}$ tient Educ Couns. 2012;89(3):363-367.

80. Davis EL, Oh B, Butow PN, Mullan BA, Clarke S. Cancer patient disclosure and patient-doctor communication of complementary and alternative medicine use: a systematic review. Oncologist. 2012; 17(11):1475-1481.

81. Evans M, Sharp D, Shaw A. Developing a model of decisionmaking about complementary therapy use for patients with cancer: a qualitative study. Patient Educ Couns. 2012;89(3):374-380.

82. Frenkel M, Ben-Arye E, Cohen L. Communication in cancer care: discussing complementary and alternative medicine. Integr Cancer Ther. 2010;9(2):177-185.

83. Oh B, Butow P, Mullan B, et al. Patient-doctor communication: use of complementary and alternative medicine by adult patients with cancer. J Soc Integr Oncol. 2010;8(2):56-64.

84. Popper-Giveon A, Schiff E, Ben-Ayre E. I will always be with you: traditional and complementary therapists' perspectives on patienttherapist-doctor communication regarding treatment of Arab patients with cancer in Israel. Patient Educ Couns. 2012;89(3):381386.

85. Schofield P, Diggens J, Charleson C, Marigliani R, Jefford M. Effectively discussing complementary and alternative medicine in a conventional oncology setting: communication recommendations for clinicians. Patient Educ Couns. 2010;79(2):143-151.

86. Tasaki K, Maskarinec G, Shumay DM, Tatsumura Y, Kakai H. Communication between physicians and cancer patients about complementary and alternative medicine: exploring patients' perspectives. Psychooncology. 2002;11(3):212-220.

87. Zhang Y, Peck K, Spalding M, Jones B, Cook RL. Discrepancy between patients' use of and health providers' familiarity with CAM. Patient Educ Couns. 2012;89(3):399-404.

88. Wilkinson S, Gomella LG, Smith JA, et al. Attitudes and use of complementary medicine in men with prostate cancer. J Urol. 2002; 168(6):2505-2509.

89. Taylor SE, Brown JD. Illusion and well-being: a social psychological perspective on mental health. Psychol Bull. 1988;103(2):193210.

90. Innes S, Payne S. Advanced cancer patients' prognostic information preferences: a review. Palliat Med. 2008;23(1):29-39.

91. Lin HR, Bauer-Wu SM. Psycho-spiritual well-being in patients with advanced cancer: an integrative review of the literature. $J A d v$ Nurs. 2003;44(1):69-80.

92. Arthur K, Belliard JC, Hardin SB, Knecht K, Chen CS, Montgomery S. Practices, attitudes, and beliefs associated with complemetnary and alternative medicine (CAM) use among cancer patients. Integr Cancer Ther. 2012;11(3):232-242.

93. Johnson S. Hope in terminal illness: an evolutionary concept analysis. J Palliat Nurs. 2007;13(9):451-459.

94. Deng G, Frenkel M, Cohen L, et al; Society for Integrative Oncology. Evidence-based clinical practice guidelines for integrative oncology: complementary therapies and botanicals. J Soc Integr Oncol. 2009;7(3):85-120.

95. Ajzuddin, Saraf S. Legal regulations of complementary and alternative medicines in difference countries. Pharmacogn Rev. 2012; 6(12):154-160.

96. McCune JS, Hatfield AJ, Blackburn AA, Leith PO, Livingston RB, Ellis GK. Potential of chemotherapy-herb interactions in adult cancer patients. Support Care Cancer. 2004;12(6):454-462. 